\title{
A relação entre as espécies de Vochysia (Vochysiaceae) e a contaminação de alumínio no solo no Estado da Bahia
}

\author{
Monick Lima Carvalho $^{1}$; Flávio França ${ }^{2}$ \\ 1. Bolsista PIBIC/CNPq, Graduando em Ciências Biológicas, Universidade Estadual de Feira de Santana, e-mail: \\ monicklimacarvalho@hotmail.com \\ 2. Orientador, Departamento de Ciências Biológicas, Universidade Estadual de Feira de Santana, e-mail: franca.flavio@.gmail.com
}

\section{PALAVRAS-CHAVE: Vochysia, alumínio, Bahia.}

\section{INTRODUÇÃO}

A família Vochysiaceae abrange oito gêneros e mais de 200 espécies, são eles: Callisthene, Erisma, Qualea, Ruizterania, Salvertia, Vochysia. As espécies que representam a família podem ser facilmente encontradas no Cerrado Brasileiro, onde se destacam espécies de Qualea, conhecidas popularmente como pau-terra e Vochysia, conhecidas como pau-de-tucano e cambará. Em geral a utilidade econômica da família é o uso da madeira, pouco encontrada como parte de ornamentação (Souza \& Lorenzi, 2005)

Os gêneros de Vochysiaceae são plantas lenhosas com folhas simples, de disposição principalmente oposta ou verticilada, com estípulas pequenas ou não. Flores grandes e vistosas, amarelas ou branco-amareladas, fortemente zigomorfas, cíclicas, diclamídeas, hermafroditas, com 1 ou 5 pétalas. Sépala externa apresenta com uma grande espora (cálcar). Androceu formado por um único e grande estame. Ovário súpero tricarpelar, trilocular, com vários óvulos. Fruto seco, capsular loculicida, com sementes unilateralmente aladas. (Joly, 1975)

Dentre as espécies de plantas que são geralmente encontradas em dunas e restingas no Brasil, algumas do gênero Vochysia (Vochysiaceae) são comuns.Este gênero engloba c. 100 espécies bem distribuídas na diversas regiões do Brasil, especialmente nos ecossistemas de cerrado do Brasil Central (Barroso, 1984) e 19 que ocorrem no estado da Bahia (Stafleu, 1948). Segundo França (2015) apenas Vochysia lucida e V. riedeliana ocorrem em áreas de restinga na Bahia

Algumas espécies de Vochysiaceae desenvolveram resistência a um dos elementos mais prejudiciais às plantas, o alumínio. Ele é um dos elementos de alto índice de toxicidade ao solo, e consequentemente às plantas. Encontrado em grande quantidade nos solos brasileiros, pois é um dos materiais encontrados nas rochas intemperizadas. $\mathrm{O}$ Al é prejudicial ao crescimento e desenvolvimentos da maioria das plantas, no entanto, uma pequena porção de plantas desenvolveu resistência, e até mesmo uma dependência ao elemento, como algumas espécies de Vochysiaceae. (Miguel et al. 2010).

Diante do fato das Vochysiaceae apresentarem uma associação com contaminação de alumínio no solo, a partir do mapeamento da ocorrência das espécies será possível mapear a contaminação de alumínio. Permitindo melhor planejamento da expansão da fronteira agrícola. Para tanto é necessário identificar as espécies de Vochysiacae que apresentam tolerância ao alumínio. Depois disso, mapeia-se os nichos de ocorrência dessas espécies e teremos uma visão bastante próxima da realidade da contaminação de alumínio nos solos do estado da Bahia. 


\section{MATERIAL E MÉTODOS OU METODOLOGIA (ou equivalente)}

Foram identificadas e localizadas populações de Vochysiaceae ao longo do estado Bahia. As populações foram selecionadas a partir a distribuição das coletas de Vochysiaceae depositadas nos herbários brasileiros, utilizando-se o sítio eletrônico Specieslink (SpeciesLink, 2015). Depois as espécies foram distribuidas no estado utilizando-se o aplicativo TrackMaker (TrackMaker, 2015). Espécies com grandes populações foram visitadas e o solo associado a elas coletado. A coleta do solo foi realizada com o uso de um trado. Em cada população foram colhidas duas amostras, sendo um ponto distante $20 \mathrm{~m}$ do outro. As duas amostras foram colhidas até uma profundidade de $40 \mathrm{~cm} \mathrm{e}$ misturadas.

As amostras de solo foram enviadas ao laboratório da Embrapa em Cruz das almas (BA). Os testemunhos de Vochysiaceae foram depositados no Herbário da Universidade Estadual de Feira de Santana (HUEFS).

As descrições das espécies de Vochysiaceae foram realizadas através de comparações com amostras já descritas e com base na literatura (Stafleu, 1948).

\section{RESULTADOS E/OU DISCUSSÃO (ou Análise e discussão dos resultados)}

Foram realizadas pesquisas através do sítio eletrônico Specieslink (Specieslink, 2015) para identificar e localizar espécies de Vochysiaceae no estado Bahia, para que estas pudessem ser coletadas. Verificou-se a presença de espécies nas regiões da Planície Litoranea, Chapada Diamantina, e Oeste da Bahia, onde realizamos a coleta de 12 amostras de solo em diferentes espécies de Vochysiaceae, sendo que a maioria das espécies foi de Qualea e Vochysia, dois dos cinco gêneros de Vochysiaceae que ocorrem no Brasil (Flora do Brasil, 2016) duas delas estão aparentemente relacionadas a altos teores de aluminio (Qualea cryptantha e Qualea cordata), as espécies Vochysia riedeliana e Vochysia obovata aparecem em áreas de altas concentrações de aluminio e também em áreas que apresentam um teor de aluminio baixo. As demais espécies (Vochysia thyrsoidea, Vochysia gardneri, Vochysia lucida, Salvertia convalliodora e Callisthene fasciculata) apresentam pouca ou nenhuma adaptação a teores elevados de aluminio. Verificou-se uma possível relação entre níveis de $\mathrm{pH}$ e concentrações de alumínio, em regiões onde havia baixo teores de alumínio, o níveis de $\mathrm{pH}$ encontravam-se elevados, demonstrando que em solos ácidos o teor de alumínio tende a ser menor.

Foram realizadas descrições de algumas espécies encontradas no Herbário da Universidade Federal de Sergipe (ASE), durante visita ao mesmo. Além disso, foram realizadas descrições em espécies de Vochysiaceae encontradas no Herbário da Universidade Estadual de Feira de Santana (HUEFS).

\section{Vochysia lucida Presl.}

Árvore 4-12m. Indumento dos ramos glabro. Cortex piloso, acastanhado. Estipulas 0,1 - 0,2 cm, lanceolada, pilosa. Peciolo 0,2-0,4 cm. Folhas simples, verticiladas, limbo obovado, 7-12 x 5-6cm, ápice arredondado-emarginado, margem inteira, base obtusa-cordada, face adaxial glabra, face abaxial glabra. Inflorecência terminal, axilar, multiplas flores amarelas, pétala $0,3 \mathrm{~cm}$, ovado ou ovado-lanceolado.

Material examinado: Sergipe, Itabaiana, E.M. Carneiro 120 (ASE), Parque Nacional da Serra de Itabaiana, $-10.773056 \mathrm{~S}-37.355833 \mathrm{~W}$

Sergipe, Serra de Itabaiana, W, E.Gomes 238 (ASE), Cerrado, 10 45' 83" S 37 20' 81" W, G. Viana1983

Sergipe, São Cristovão, G. Viana 789 (ASE), Cerrado, 11 00' 53" S 37 12' 23" W, F. França 1995.

\section{Vochysia thyrsoidea Pohl.}

Árvore 5-7m. Indumento dos ramos glabro. Estipulas $0,1 \mathrm{~cm}$, lanceolada, pilosa. Peciolo $0,4-1,4 \mathrm{x}$ $0,2-0,3 \mathrm{~cm}$. Folhas verticiladas, limbo obovado, $6-9$ x 4-5cm, coriécea, ápice arredondadoemarginado, base cuneada. Inflorecência terminal, 3-5 flores vistosas, $6 \mathrm{~cm}$, pedicelo 1-2 x 0,1-0.2 $\mathrm{cm}$. pétala glabra, linear-oblonga. 
Material examinado: Ceará, D. de Andrade-Lima 1297 (ASE), enconsta da Sera do Araripe.Mata do terço superior, Crato, -7.234444 S -39.409167 W, F.França 1995.

Sergipe, Areia Branca, W.J. Machado 1165 (ASE), Serra de Itabaiana, Mata Atlântica, -10.685278 S -37.425 W, Alt.: 9999m, W.J Machado 2013.

3. Vochysia obovata Stafl. nov. spec.

Árbusto 1,5-3m. Indumento dos ramos glabro.Estipulas $0,1-0,1 \mathrm{~cm}$, deltoides. Peciolo 0,8 - 1,5 $\mathrm{cm}$. Folhas verticiladas, oblanceolada ou obovado, margem inteira, ápice emarginado, base atenuada ou obtuso-cordada, aguda, fortemente coriácea, pecíolo curto, face adaxial glabra, face abaxial glabra. Inflorescência terminal, racemo de cincinio, com pedicelos de 1-1.5 cm; botões glabros, flores amarelo-ouro, pétalas basais, laranja-avermelhadas.

Material examinado: Bahia, Abaíra, W. Ganev 2714 (HUEFS), campos do virasaia, 132 21' S $41^{\circ}$ 50' W, alt.1530, F. França 1997.

Bahia, Mucugê, A.M. Carvalho 2935 (HUEFS), -13.0053 S -41.3708 W, F.França 1999.

\section{Vochysia gardneri Mart}

Árbusto ou árvore 1,5-3m. Indumento dos ramos glabro ou vetutino denso. Pecíolo $1-1,2 \mathrm{~cm}$. Folhas verticiladas, oval, 6,5-13,5 × $3-6 \mathrm{~cm}$, margem inteira, ápice emarginado, base cuneada, face adaxial glabra ou pubescente esparço, face abaxial glabra. Inflorescência terminal, $20 \mathrm{~cm}$.

Material examinado: Bahia, Correntina, R. M. Harley et al. 28529 (HUEFS), $27 \mathrm{Km}$ do entroncamento com Br 020 e Br 349, 13 43' 9" S 45 55' 17" W, F. França 1999

Bahia, Cocos, França et al. 3606 (HUEFS), Riacho do meio, 14 $15^{\prime} 25^{\prime \prime} \mathrm{S} 44^{\circ} 40^{\prime} 29^{\prime \prime} \mathrm{W}$, alt. 520, F. França 2001.

\section{Vochysia riedeliana Stafl.}

Arvore de grande porte. Estipulas 0,2 - 0,3 cm. Peciolo 0,5 - $2 \mathrm{~cm}$, glabro. Folhas verticiladas, 15 20 x $5-7 \mathrm{~cm}$ ápice arredondado-retuso ou emarginado, base atenuada. Inflorescência terminal, racemo de cincinio, $2-5$ flores, pedicelos $0,4-1,5 \mathrm{~cm}$, petalas obovadas, glabras, com ápice arredondado.

Material examinado: Bahia, Candeias, M.A. Mayworm 92 (HUEFS), Br 324, km 569, -12.6678 S -38.5506 W, F. França 1997.

Bahia, Amélia Rodrigues, L.P. Queiroz 1456, -12.433333 S -38.733333 W. M.C. Vianna 2000.

\section{Vochysia pyramidalis Mart}

Árvore 2 - $9 \mathrm{~m}$. Estipulas 0,2 - 0,4 cm. Peciolo 0,6 - 1,2 cm. Folhas oposta, lanceolada-obovado, margem inteira, ápice águdo ou acuminado, base arrendondada, coriácea, face adaxial glabra, verde intenso, face abaxial pubescente. Inflorescência terminal, racemo de cincinio, $1-5$ flores amareloouro, com pedicelos de $1-1,7 \mathrm{~cm}$; flores amarelo-ouro, pétalas membranaceas, ápice obtuso ou arredondado.

Material examinado: Bahia, Rio de Contas, M.A. Mayworm 70 (HUEFS), Cachoeira Fraga, -13.5789 S -41.8114 W, F.França 1998

Bahia, Mucugê, Melo, E. 12000, Alagados do rio Paraguaçu, beira da lagoa, -13.016667 S -41.4275 W, Alt. 1001 
Foram alcançados resultados satisfatórios, no que esperava-se em respeito a relação do teor de alumínio nas espécies de Vochysia, assim como a realização da descrição das espécies de Vochysia relacionadas a teor de aluminio no solo.

\section{REFERÊNCIAS}

Barroso, G. et al. Sistemática de Angiospermas do Brasil. Vol. 2. Viçosa: UFV, 1984

Flora do Brasil. $<>$, acesso em fev de 2016

França, F. Vochysiaceae in Lista de Espécies da Flora do Brasil. Jardim Botânico do Rio de Janeiro. Disponível em: <http://floradobrasil.jbri.gov.br/jabot/floradobrasil/FB250>. Acesso em: 04 Abr. 2015

Joly, Aylton Brandão, 1924-1975. Botânica: introdução à taxonomia vegetal/ Aylton Brandão Joly; ilustrações de Irina Gemtchujnikov. 11 ed. - São Paulo: Editora Nacional, 1993. (página 416)

Miguel,Paulo; Gomes, Fernando; Rocha, Wadson; Martins, Carlos; Carvalho, Caio; Oliveira André. Efeitos tóxicos do Alumínio no crescimento das plantas: mecanismos de tolerância, sintomas, efeitos fisiológicos, bioquímicos e controle genético. CES revista, v. 24, p. 13-30, 2010.

Souza, Vinicius Castro. Botânica sistemática: guia ilustrado para identificação das famílias de angiospermas da flora brasileira, baseado em APG II/ Vinicius Castro Souza, Harri Lorenzo Nova Odessa, SP: Instituto Plantarum, 2005.

Specieslink. <WWW.splink.org.br>, acesso em 12 fev 2015.

Stafleu, F. A monograph of the Vochysiaceae I: Salvertia and Vochysia. Rec. Trav. Bot. Neerl. 41: 395-540, 1948

Trackmaker. <WWW.trackmaker.com>, acesso 12 fev 2015. 